\title{
Spirulina protein promotes skin wound repair in a mouse model of full-thickness dermal excisional wound
}

\author{
PING LIU ${ }^{1,2}$, JEONG-WOOK CHOI $^{3}$, MIN-KYEONG LEE $^{3}$, YOUN HEE CHOI $^{3,4}$ and TAEK-JEONG NAM ${ }^{1,3}$
${ }^{1}$ Department of Food Science and Nutrition, Pukyong National University, Busan 48513, Republic of Korea;
${ }^{2}$ Department of Food Science and Engineering, Qingdao Agricultural University, Qingdao, Shandong 266109, P.R. China;
${ }^{3}$ Institute of Fisheries Sciences, Pukyong National University, Busan 46041; ${ }^{4}$ Department of Marine Bio-Materials \\ and Aquaculture, Pukyong National University, Busan 48513, Republic of Korea
}

Received January 8, 2020; Accepted April 2, 2020

DOI: $10.3892 /$ ijmm.2020.4571

\begin{abstract}
The skin protects body from environmental damage. Skin wounds lead to microbial infection and harmful agent injury. Thus, wound repair is crucial for the recovery of the normal function of skin tissue. The present study investigated the promoting effects of spirulina protein (SPCP) in mice on skin wound repair and also aimed to elucidate the potential underlying mechanisms. The results revealed that SPCP promoted the skin wound repair in a mouse model of full-thickness excisional wounds. SPCP induced an increase in the expression level of $\alpha$-smooth muscle actin ( $\alpha$-SMA). The activities of superoxide dismutase (SOD) and catalase (CAT) were enhanced by SPCP treatment in the granulation tissue. In addition, SPCP decreased the level of malondialdehyde (MDA) in the granulation tissue. Western blot analysis revealed that SPCP enhanced the phosphorylation and activation of protein kinase B (Akt) and extracellular signal-regulated kinase (ERK). Moreover, the expression level of transforming growth factor $\beta 1$ (TGF- $\beta 1$ ) was increased in the SPCP-treated groups. The phosphorylation level of Smad2 was also increased by treatment of SPCP. Furthermore, SPCP promoted the expression of collagen in the granulation tissue. Taken together, these findings indicate that SPCP exerts a promoting effect on skin wound repair. The Akt, ERK and TGF- $\beta 1$ signaling pathways are involved in this process.
\end{abstract}

Correspondence to: Professor Taek-Jeong Nam, Department of Food Science and Nutrition, Pukyong National University, 599-1 Daeyeon 3-Dong, Nam-gu, Busan 48513, Republic of Korea E-mail:namtj@pknu.ac.kr

Professor Youn Hee Choi, Institute of Fisheries Sciences, Pukyong National University, 599-1 Daeyeon 3-Dong, Nam-gu, Busan 46041, Republic of Korea

E-mail: unichoi@pknu.ac.kr

Key words: skin wound, skin wound repair, spirulina crude protein, protein kinase B, extracellular signal-regulated kinase; transforming growth factor $\beta 1$

\section{Introduction}

Skin serves as the protective barrier of the body and protects it from harmful agents, such as ultraviolet (UV) radiation, heat and microorganisms $(1,2)$. Damage to the skin tissue not only causes damage to the subcutaneous tissue, but also affects the internal balance of the body $(3,4)$. Thus, skin wound repair is crucial for the restoration of the protective functions of the skin. Wound repair requires a cascade of phases, including inflammation, proliferation and remodeling $(5,6)$. Various growth factors and cytokines are released during these processes. Transforming growth factor $\beta 1$ (TGF- $\beta 1$ ), a highly multifunctional cytokine, affects all 3 phases of wound repair (7-9). The extracellular matrix (ECM) of the dermis is produced by fibroblasts and consists of collagen, elastin and proteoglycans $(10,11)$. Skin fibrosis is caused by an imbalance between the generation and degradation of ECM proteins, which results in the severe alteration of the skin connective tissue and delays wound repair (12-14). However, the deposition of ECM components is regulated by TGF- $\beta 1$ in the wound repair process (15). Its downstream signaling Smad2 is phosphorylated by activated TGF- $\beta 1$. The target genes are then induced to promote wound repair $(16,17)$. During wound repair, fibroblasts can be activated and become myofibroblasts. These myofibroblast cells can synthesize ECM and play a positive role in the contraction of granulation tissue. The expression of $\alpha$-smooth muscle actin ( $\alpha$-SMA) is a specific marker of myofibroblasts. Moreover, the differentiation of fibroblasts to $\alpha$-SMA is promoted by TGF- $\beta 1$ (18).

Reactive oxygen species (ROS) function as secondary messengers in a number of cells, including immunocytes and non-lymphoid cells (19). These cells play a positive role in tissue repair, and then promote wound repair $(19,20)$. ROS play a beneficial role in protecting against invading bacteria in wound repair. Appropriate levels of ROS are beneficial for wound repair. However, excessive ROS production leads to oxidative stress, and inhibits the proliferation and migration of cells in wound repair $(21,22)$. In addition, high levels of oxidative stress prolong the inflammatory process, induce tissue damage and results in the delay of wound repair. Thus, it is necessary to control the levels of ROS during wound repair $(23,24)$. 
Spirulina, a blue-green algae, has been used as a food source since ancient times. It is commercialized for abundant proteins, vitamins and minerals. Moreover, spirulina has been reported to exhibit pharmaceutical potential due to its anti-inflammatory, antioxidant and anticancer properties $(25,26)$. Recently, the promoting effects of spirulina protein (SPCP) on the activity of CCD-986sk human fibroblasts were demonstrated (27). Furthermore, SPCP was shown to improve collagen formation in CCD-986sk cells and to decrease the activity of elastase, which plays an important positive role in wound repair (27). In addition, the migration and proliferation of CCD-986sk cells have been shown to be promoted by SPCP via phosphoinositide 3-kinase (PI3K)/protein kinase B (Akt) signaling pathway (28). These effects of SPCP on human fibroblasts provide a possible application for promoting skin wound repair.

Herein, the aim of the present study was to examine the promoting effects of SPCP on skin wound repair. A mouse model of full-thickness dermal excisional wounds using C57BL/6 mouse was established. In addition, the underlying molecular mechanisms of this process were investigated. The main findings suggested that SPCP can promote the skin wound repair in C57BL/6 mice, and that the extracellular signal-regulated kinase (ERK), Akt and TGF- $\beta 1$ signaling pathways were activated by SPCP during this process.

\section{Materials and methods}

Experimental animals. All experiments procedures were approved by the University Animal Care and Use Committee guidelines at Pukyong National University (Busan, Korea; approval no. 2018-15) and conducted according to the international regulations of the usage and welfare of laboratory animals. A total of 20 C57BL/6 male mice (6 weeks old; weighing 20-23 g) were obtained from IDEXX Bioresearch, and maintained under controlled conditions with proper temperature $\left(22^{\circ} \mathrm{C}\right)$ and humidity $(40-45 \%)$ under a light/dark cycle of $12 \mathrm{~h} / 12 \mathrm{~h}$. They were kept in single-house and provided with standard rodent food and water ad libitum.

Establishment of full-thickness excisional wounds. All 20 mice were allowed to adapt to their new environment for 1 week. Mice were anesthetized with ether (2-4\% in an inhaled mixture). The lack of a toe pinch reflex ensured that the mouse was fully anesthetized. The hair of the dorsal surface was removed using an electric clipper. The dorsal skin of each mouse was rinsed using alcohol, and a 8-mm-diameter biopsy punch was then used to create a full-thickness wound on the backs of the mice. All the mice were randomly divided into 4 groups with 5 mice in each group. The first group was the control group in which mice were treated with vaseline (British-Dutch company, Unilever) only. The second group was the positive control group in which mice were treated with vaseline containing $10 \mu \mathrm{g} / \mathrm{g}$ epidermal growth factor (EGF) (Sigma-Aldrich; Merck KGaA). The third group was the sample group in which mice were treated with vaseline containing 2\% SPCP. The fourth group was the sample group in which mice were treated with vaseline containing $4 \%$ SPCP. Vaseline, EGF or SPCP was applied directly to the wound site once a day. Wound repair was macroscopically monitored by obtaining images with a digital camera (Sony HDR-XR260;
Sony Corporation) at 1 p.m. each day. After 9 days, all 20 mice were euthanized by cervical dislocation. Respiratory arrest and the absence of blinking confirmed the mouse death. The skin around the wound was collected and treated with liquid nitrogen. The collected skin tissues were stored at $-70^{\circ} \mathrm{C}$ for use in the subsequent experiments. The wound areas were calculated using ImageJ software (version 1.40; National Institutes of Health). The results were expressed as the percentage of the original size.

Measurement of superoxide dismutase (SOD) activity. The SOD Activity Assay kit (BioVision, Inc.) was used to determine the activity of SOD in the mouse skin tissue by ELISA. Firstly, PBS was used to remove any red blood cells. The skin tissue was then homogenized with ice-cold $\left(0-4^{\circ} \mathrm{C}\right) 0.1 \mathrm{~mol} / \mathrm{l}$ of Tris/ $\mathrm{HCl}[\mathrm{pH} 7.4$, containing $5 \mathrm{mmol} / \mathrm{l}$ of $\beta$-mercaptoethanol $(\beta-\mathrm{ME}), 0.5 \%$ Triton X-100 and $0.1 \mathrm{mg} / \mathrm{ml}$ phenylmethylsulfonyl fluoride (PMSF)]. It was subsequently centrifuged at $14,000 \mathrm{xg}$ for $5 \mathrm{~min}$ at $4^{\circ} \mathrm{C}$. The supernatant was used to determine the activity of SOD. The supernatant from 4 groups was plated in 96-well plates; i.e., sample, blank 1,2 and 3. A total of $20 \mu \mathrm{l}$ of sample solution were added to each well of the sample group and blank 2 group, respectively. This was followed by the addition of $20 \mu \mathrm{l}$ of $\mathrm{ddH}_{2} \mathrm{O}$ to each well of the blank 1 group and blank 3 group, respectively. Each of the above wells was then supplemented with $200 \mu 1$ of dilution buffer. A total of $20 \mu \mathrm{l}$ of enzyme working solution (BioVision, Inc.) was then added to each well of the sample group and blank 1 group. The plate was then incubated at $37^{\circ} \mathrm{C}$ for $20 \mathrm{~min}$. The Synergy HTX microplate reader (BioTek Instruments, Inc.) was used to measure the absorbance at $450 \mathrm{~nm}$. The activity of SOD was calculated according to the manufacturer's instructions.

Measurement of catalase (CAT) activity. The activity of CAT was determined using the Catalase Activity Colorimetric/Fluorometric Assay kit (BioVision, Inc.) by ELISA. The skin tissue was homogenized with ice-cold assay buffer. It was subsequently centrifuged at $10,000 \mathrm{x} \mathrm{g}$ for $5 \mathrm{~min}$ at $4^{\circ} \mathrm{C}$. The supernatant was used to determine the activity of CAT. Each of the sample wells was supplemented with $50 \mu \mathrm{l}$ of Sample Solution and the positive control well was supplemented with $3 \mu \mathrm{l}$ of positive control solution (BioVision, Inc.). Each of the wells was supplemented with assay buffer to the final volume of $78 \mu 1$. The sample high control well was supplemented with $50 \mu 1$ of sample solution and then supplemented with assay buffer to the final volume of $78 \mu 1$. The sample high control well was then supplemented with $10 \mu \mathrm{l}$ of stop solution. After mixing, the plate was incubated at $25^{\circ} \mathrm{C}$ for $5 \mathrm{~min}$ to inhibit the activity of CAT adequately. This was followed by the addition of $12 \mu \mathrm{l}$ of $1 \mathrm{mmol} / 1 \mathrm{H}_{2} \mathrm{O}_{2}$ to each well (sample well, positive control well and sample high control well). The plate was then incubated at $25^{\circ} \mathrm{C}$ for $30 \mathrm{~min}$. Subsequently, $10 \mu \mathrm{l}$ of stop solution were added to sample well and positive control well. A total of $50 \mu \mathrm{l}$ of Develop Mix (46 $\mu 1$ of Assay Buffer, $2 \mu 1$ of OxiRedTM Probe and $2 \mu \mathrm{l}$ of HRP solution) were then added to each well and incubated at $25^{\circ} \mathrm{C}$ for $10 \mathrm{~min}$. The Synergy HTX microplate reader (BioTek Instruments, Inc.) was used to measure the absorbance at $570 \mathrm{~nm}$. The activity of CAT was calculated according to the manufacturer's instructions. 
Table I. Primary antibodies used in western blot analysis.

\begin{tabular}{llc}
\hline Name of primary antibody & \multicolumn{1}{c}{ Manufacturer and cat. no. } & Dilution rate \\
\hline GAPDH & Santa Cruz Biotechnology: sc-25778 & $1: 1,000$ \\
p-ERK & Santa Cruz Biotechnology: sc-7383 & $1: 1,000$ \\
ERK1 & Santa Cruz Biotechnology: sc-271269 & $1: 1,000$ \\
ERK2 & Santa Cruz Biotechnology: sc-154 & $1: 1,000$ \\
p-Akt & Santa Cruz Biotechnology: sc-514032 \\
Akt & Santa Cruz Biotechnology: sc-8312 & $1: 500$ \\
$\alpha$-actin & Santa Cruz Biotechnology: sc-32251 & $1: 500$ \\
TGF- $\beta 1$ & Santa Cruz Biotechnology: sc- 146 & $1: 1,000$ \\
p-Smad2 & Santa Cruz Biotechnology: sc-135644 & $1: 1,000$ \\
Smad2 & Santa Cruz Biotechnology: sc-6200 & $1: 1,000$ \\
COL1A1 & Santa Cruz Biotechnology: sc-293182 & $1: 1,000$ \\
COL1A2 & Santa Cruz Biotechnology: sc-376350 & $1: 500$
\end{tabular}

Measurement of the malondialdehyde (MDA) level. The level of MDA was determined using the Lipid Peroxidation (MDA) Colorimetric/Fluorometric Assay kit (BioVision, Inc.) by ELISA. The skin tissue was homogenized with MDA Lysis Buffer. It was subsequently centrifuged at 13,000 x g for $10 \mathrm{~min}$. A total of $200 \mu \mathrm{l}$ of supernatant was then place in a $1.5 \mathrm{ml}$ microcentrifuge tube. Thiobarbituric acid (TBA; $600 \mu \mathrm{l})$ was then added to each well and incubated at $95^{\circ} \mathrm{C}$ for $60 \mathrm{~min}$. The sample was placed in the ice for $10 \mathrm{~min}$ and thawed to the room temperature $\left(20-25^{\circ} \mathrm{C}\right)$. A total of $200 \mu 1$ was taken from $800 \mu \mathrm{l}$ reaction mixture to a 96 -well plate for analysis. The Synergy HTX microplate reader (BioTek Instruments, Inc.) was used to measure the absorbance at $532 \mathrm{~nm}$. The level of MDA was calculated according to the manufacturer's instructions.

Preparation of whole cell lysates. Skin tissue was minced and homogenized using RIPA buffer (iNtRON Biotechnology) with $1 \%$ protease inhibitor in an ice-bath. Subsequently, the extract was incubated in ice and then centrifuged at $16,000 \mathrm{x} \mathrm{g}$ for $10 \mathrm{~min}$ at $4^{\circ} \mathrm{C}$. The supernatant was collected as the protein. The BCA protein assay kit (Pierce; Thermo Fisher Scientific, Inc.) was used to analyze the concentration of the protein. The protein concentration of different treatment groups was adjusted to the same level. The protein solution was then mixed with SDS sample buffer containing DTT and denatured at $100^{\circ} \mathrm{C}$ for $5 \mathrm{~min}$.

Western blot analysis. SDS-PAGE gel (7.5-12.5\%) was used to separate proteins (30 $\mu \mathrm{g}$ per lane). The proteins were then transferred to PVDF membranes (EMD Millipore). Membranes were washed with methanol, and then blocked for $2 \mathrm{~h}$ with TBS-T [10 mm Tris- $\mathrm{HCl}, 150 \mathrm{~mm} \mathrm{NaCl}(\mathrm{pH} 7.5)$ and $0.1 \%$ Tween-20] containing $1 \%$ BSA. The membrane were then incubated at $4^{\circ} \mathrm{C}$ overnight $(\geq 12 \mathrm{~h})$ with primary antibodies. After washing 2 times with TBS-T for 15 min each time, the membranes were incubated at room temperature for a further $2 \mathrm{~h}$ with the secondary antibodies (all 1:10,000). The secondary antibodies used were HRP-conjugated anti-rabbit IgG (cat. no. 7074S, Cell Signaling Technology, Inc.), donkey anti-goat IgG (cat. no. A50-101p, Bethyl Laboratories, Inc.) and anti-mouse IgG (cat. no. 7076S, Cell Signaling Technology, Inc.). The primary antibodies used are listed in Table I. Color development was performed using an enhanced chemiluminescence western blot kit (Thermo Fisher Scientific, Inc.). The bioanalytical imaging system (Azure Biosystems) was used to detect the protein bands. Multi-Gauge software, version 3.0 (Fujifilm Life Science) was used to analyze the density of these protein bands. Each density of these protein bands was normalized to GAPDH.

Statistical analysis. For all assays, at least 3 independent experiments were performed. The mean \pm standard deviations of the expression values were calculated using Microsoft Excel. The differences between 2 groups were evaluated with one-way analysis of variance followed by the Bonferroni post hoc test using SPSS statistical software for Windows, v.20.0 (IBM Corp.).

\section{Results}

Treatment with SPCP accelerates wound repair. In order to determine the effects of SPCP on skin wound repair, C57BL/6 mice were used. To prove the hypothesis that SPCP promotes wound healing, full-thickness excisional wounds were created using mice. From the images obtained on days 0, 3, 6 and 9, it can be seen that the percentage wound closure in the mice which were treated with EGF or SPCP was higher than that of the mice which were treated only with Vaseline as the control (Fig. 1).

Myofibroblasts play an important role in skin wound repair. One of the myofibroblast-specific markers is $\alpha$-SMA $(18,29)$. Thus, the expression level of $\alpha$-SMA was determined by western blot analysis in the present study. As shown in Fig. 2, the expression level of $\alpha$-SMA was higher in the EGF- or SPCP-treated groups than in the control group. These results indicated that SPCP enhanced wound repair by increasing the level of myofibroblasts.

Effect of SPCP on the body weight of C57BL/6 mice. To determine the effects of SPCP on the body weight of C57BL/6 
Table II. Effect of SCPC on the body weights of C57BL/6 mice.

\begin{tabular}{lcccc}
\hline & & & \multicolumn{2}{c}{ SPCP (\%) } \\
\cline { 4 - 5 } Weight & Control & EGF & $2 \%$ & $4 \%$ \\
\hline Basal BW (g) & $22.86 \pm 0.40$ & $21.66 \pm 0.74$ & $23.00 \pm 0.41$ & $22.40 \pm 0.35$ \\
Final BW (g) & $22.92 \pm 0.68$ & $22.18 \pm 0.66$ & $23.08 \pm 0.77$ & $22.76 \pm 0.58$ \\
\hline
\end{tabular}

The results are presented as the means \pm standard deviation of 3 independent experiments.
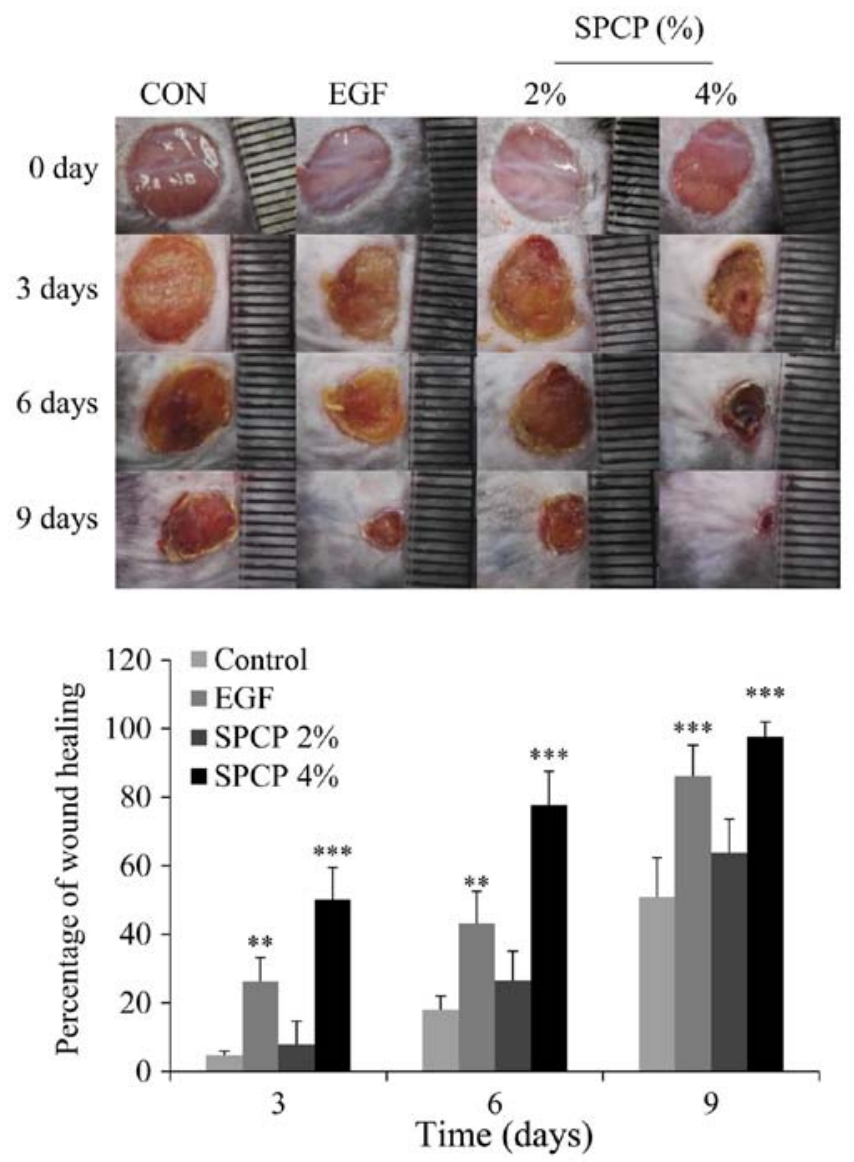

Figure 1. Treatment with SPCP enhances skin wound repair in C57BL/6 mice The effect of SPCP on the skin wound repair was measured using a full-thickness excisional wound model in C57BL/6 mouse. Each value represents the mean \pm standard deviation of 5 mice. ${ }^{* *} \mathrm{P}<0.01,{ }^{* * * *} \mathrm{P}<0.001$ compared with the control group. SPCP, spirulina protein; EGF, epidermal growth factor.

mice, the body weights of the mice were recorded. From the results (Table II) it can be seen that the body weights of the mice in the SPCP-treated group exhibited no marked differences with the mice in the control group. These results indicated that SPCP exerted no effect on the body weights of C57BL/6 mice.

Effect of 9 days of treatment with SPCP on lipid peroxide and antioxidant enzyme levels in granulation tissue homogenate. In order to determine the effects of SPCP on the activity of SOD, enzyme-linked immunosorbent assay (ELISA) was performed using an ELISA kit. As in shown in Table III, the mice which were treated with SPCP exhibited a higher
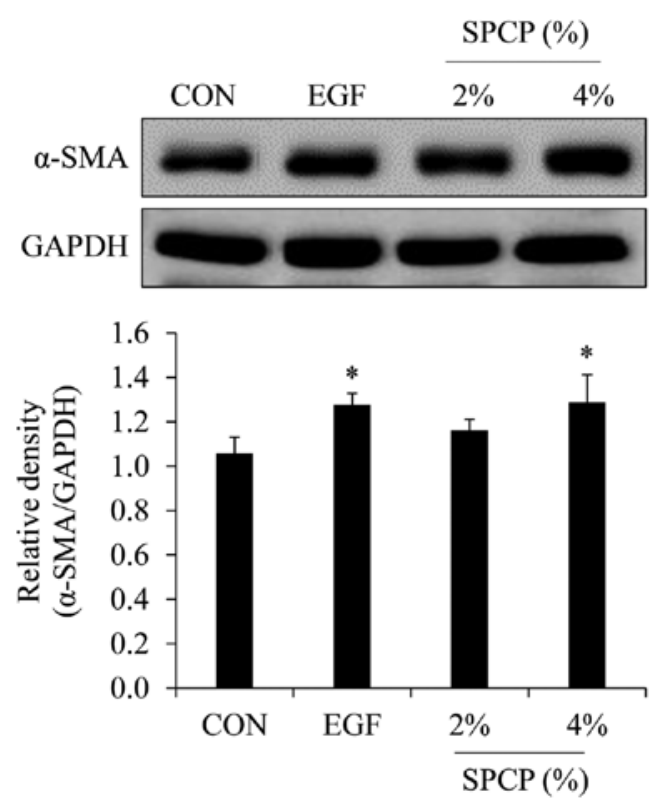

Figure 2. Treatment with SPCP induces the expression level of $\alpha$-SMA in C57BL/6 mice. The expression level of $\alpha$-SMA in C57BL/6 mice was measured by western blot analysis following treatment with various concentrations of SPCP for 9 days. Each value represents the mean \pm standard deviation of 3 independent experiments. ${ }^{*} \mathrm{P}<0.05$ compared to the control group. SPCP, spirulina protein; EGF, epidermal growth factor; $\alpha$-SMA, $\alpha$-smooth muscle actin.

activity of SOD compared with those in the control group. Furthermore, the activity of SOD was induced by SPCP in a dose-dependent manner. These results indicated that SPCP may exert a positive effect on antioxidants by enhancing the activity of SOD during skin wound repair in mice.

In order to determine the effects of SPCP on the activity of CAT, ELISA was performed using an ELISA kit. As shown in Table III, the mice which were treated with SPCP exhibited a higher activity of CAT compared with those in the control group. Furthermore, the activity of CAT was induced by SPCP in a dose-dependent manner. These results indicated that SPCP may exert a positive effect on antioxidants by enhancing the activity of CAT during skin wound repair in mice.

In order to determine the effects of SPCP on the level of MDA, ELISA was performed using an ELISA kit. As in shown in Table III, the mice which were treated with SPCP exhibited a lower level of MDA compared with those in the control group. These results indicated that SPCP may exert a positive effect on antioxidant by inhibiting the level of MDA during skin wound repair in mice. 
Table III. Effect of 9 days treatment with SPCP on lipid peroxide and antioxidant enzyme levels in granulation tissue homogenate.

\begin{tabular}{lccc}
\hline & SOD activity (U/mg protein) & CAT activity (mU/mg protein) & MDA (nmol/mg protein) \\
\hline Control & $12.55 \pm 0.08$ & $3.55 \pm 0.22$ & $0.98 \pm 0.04$ \\
EGF & $13.59 \pm 0.43^{\mathrm{a}}$ & $4.65 \pm 1.19$ & $0.64 \pm 0.08^{\mathrm{b}}$ \\
$2 \%$ SPCP & $13.87 \pm 0.53^{\mathrm{a}}$ & $4.52 \pm 0.19$ & $0.60 \pm 0.06^{\mathrm{c}}$ \\
$4 \%$ SPCP & $15.61 \pm 0.36^{\mathrm{c}}$ & $6.02 \pm 0.54^{\mathrm{b}}$ & $0.36 \pm 0.05^{\mathrm{c}}$ \\
\hline
\end{tabular}

The results are presented as the means \pm standard deviation of 3 independent experiments. ${ }^{\mathrm{a}} \mathrm{P}<0.05,{ }^{\mathrm{b}} \mathrm{P}<0.01,{ }^{\mathrm{c}} \mathrm{P}<0.001$ compared to the control group.
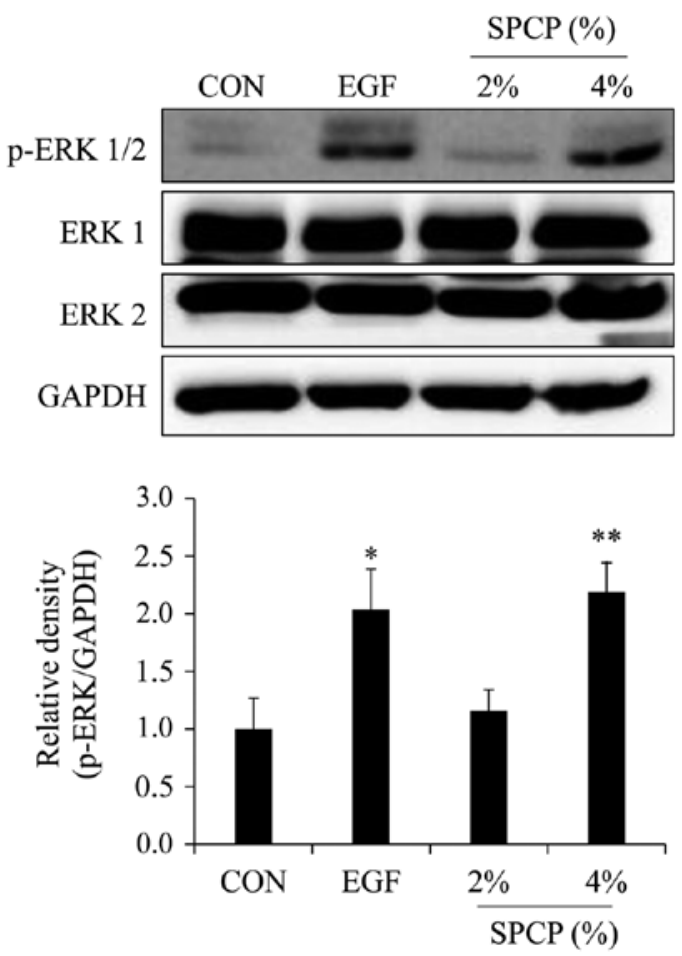

Figure 3. Treatment with SPCP enhances the phosphorylation level of ERK in C57BL/6 mice. The phosphorylation level of ERK in C57BL/6 mice was measured by western blot analysis following treatment with various concentrations of SPCP for 9 days. Each value represents the mean \pm standard deviation of three independent experiments. ${ }^{*} \mathrm{P}<0.05,{ }^{* *} \mathrm{P}<0.01$ compared to the control group. SPCP, spirulina protein; EGF, epidermal growth factor; ERK, extracellular signal-regulated kinase.

SPCP enhances wound repair via the ERK signaling pathway in C57BL/6 mice. According to previous results in CCD-986sk cells (27), it is known that the EGFR/ERK signaling pathway is involved in the SPCP-induced proliferation and migration of CCD-986sk cells. Thus, the effect of SPCP on the phosphorylation level of ERK was determined by western blot analysis. The results revealed that the phosphorylation level of ERK was increased by treatment with SPCP in the skin granulation tissue of C57BL/6 mice (Fig. 3). This indicated that SPCP promoted skin wound repair in C57BL/6 mice via the ERK signaling pathway.

SPCP enhances wound repair via the Akt signaling pathway in C57BL/6 mice. According to previous results in CCD-986sk cells (28), it is known that the PI3K/Akt signaling pathway is
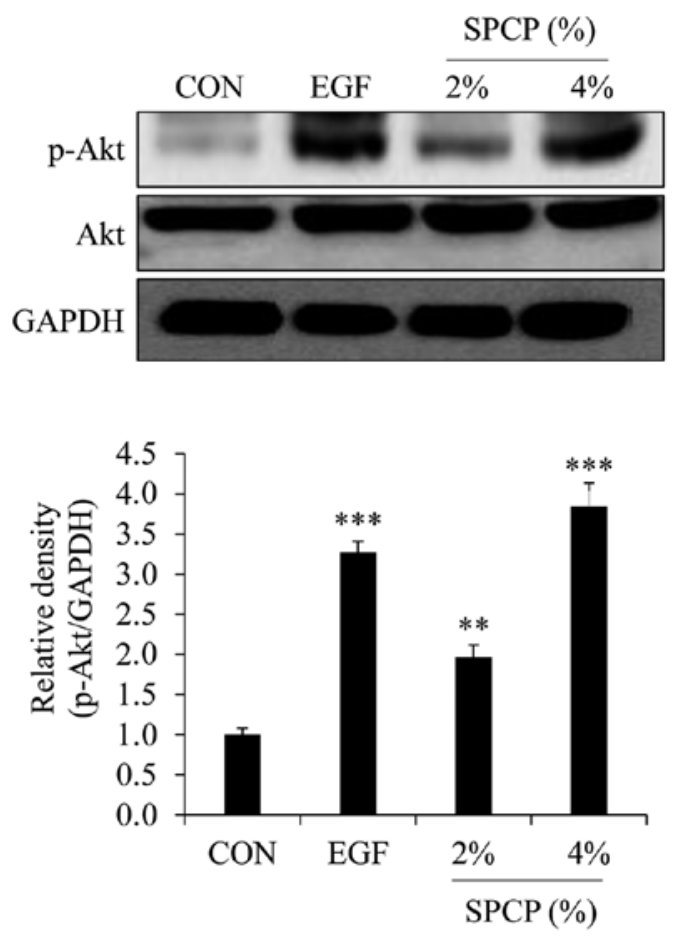

Figure 4. Treatment with SPCP enhances the phosphorylation level of Akt in C57BL/6 mice. The phosphorylation level of Akt in C57BL/6 mice was measured by western blot analysis following treatment with various concentrations of SPCP for 9 days. Each value represents the mean \pm standard deviation of three independent experiments. ${ }^{* *} \mathrm{P}<0.01,{ }^{* * * *} \mathrm{P}<0.001$ compared to the control group. SPCP, spirulina protein; EGF, epidermal growth factor; Akt, protein kinase B.

involved in the SPCP-induced proliferation and migration of CCD-986sk cells. Thus, the effect of SPCP on the phosphorylation level of Akt were determined by western blot analysis in the present study. The results revealed that the phosphorylation level of Akt was increased by treatment with SPCP in the skin granulation tissue of C57BL/6 mice (Fig. 4). This indicated that SPCP promoted skin wound repair in $\mathrm{C} 57 \mathrm{BL} / 6$ mice via the Akt signaling pathway.

SPCP enhances wound repair via the TGF- $\beta 1 /$ Smad signaling pathway. The TGF- $\beta 1 /$ Smad signal transduction pathway is a signal transduction pathway which plays an important role in tissue repair (30). TGF- $\beta 1$ is involved in the whole process of inflammation, proliferative phase and plasticization during wound repair (31). Thus, the effect of SPCP on the 
A
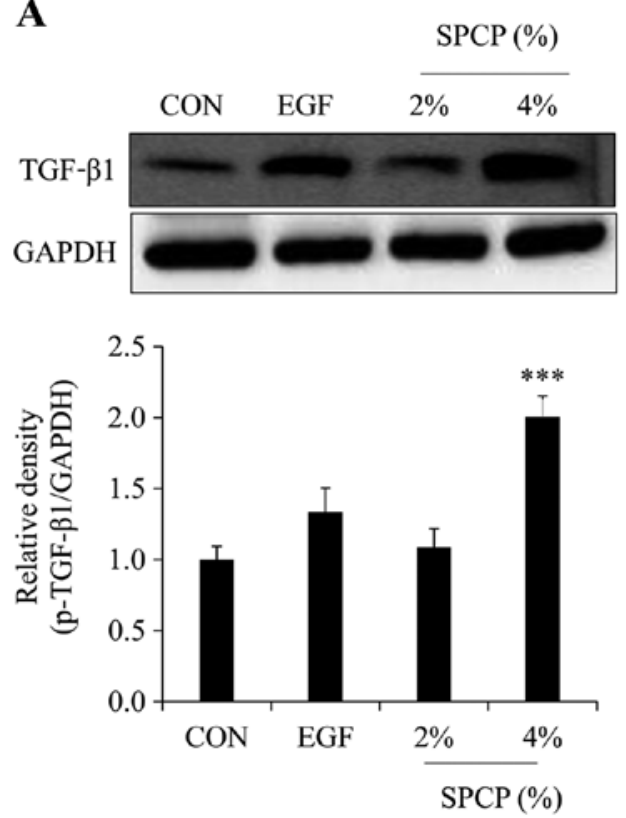

B
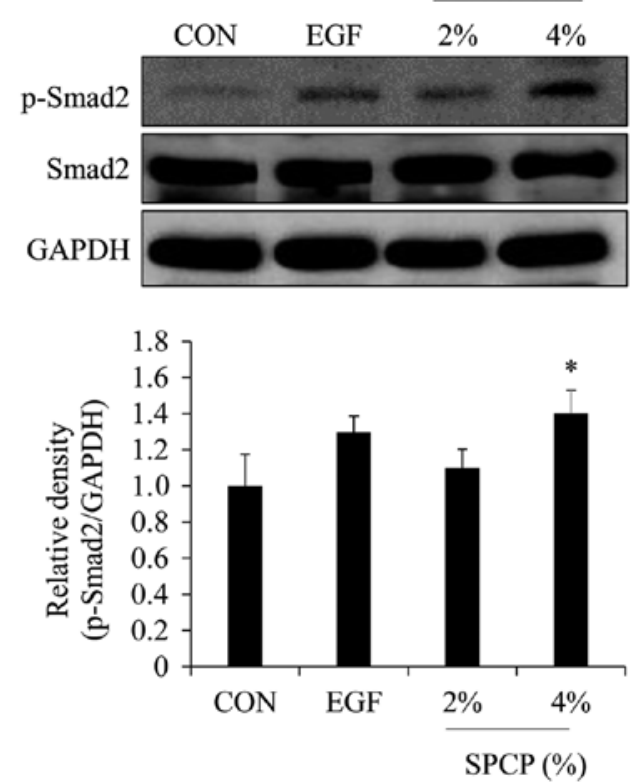

Figure 5. Treatment with SPCP induces the activation of TGF- $\beta 1 / \mathrm{Smad} 2$ signaling pathway in C57BL/6 mice. (A) The protein expression level of TGF- $\beta 1$ in C57BL/6 mice was measured by western blot analysis following treatment with various concentrations of SPCP for 9 days. (B) The phosphorylation level of Smad 2 in C57BL/6 mice was measured by western blot analysis following treatment with various concentrations of SPCP for 9 days. Each value represents the mean \pm standard deviation of three independent experiments. ${ }^{*} \mathrm{P}<0.05,{ }^{* * *} \mathrm{P}<0.001$ compared to the control group. SPCP, spirulina protein; EGF, epidermal growth factor; TGF- $\beta 1$, transforming growth factor $\beta 1$.

TGF- $\beta 1 /$ Smad signaling pathway was determined by western blot analysis in the present study. The results revealed that the level of TGF- $\beta 1$ was increased by treatment with SPCP in the skin granulation tissue of C57BL/6 mice (Fig. 5A). Moreover, the level of p-Smad2 was increased by treatment with SPCP in the skin granulation tissue of C57BL/6 mice (Fig. 5B). These results indicated that SPCP promoted skin wound repair in C57BL/6 mice via the TGF- $\beta 1 /$ Smad signaling pathway.

SPCP regulates the expression of collagen. In order to determine the effects of SPCP on the expression level of collagen in the granulation tissue of C57BL/6 mice, western blot analysis was performed. The results revealed that the expression level of type I collagen was higher in SPCP-treated group than that in the control group (Fig. 6). This result indicated that SPCP enhanced the deposition of type I collagen during skin wound repair.

\section{Discussion}

Normally, for the damage of the external environment, skin can protect the integrity and function of internal organs very effectively $(22,32)$. Therefore, in the process of resisting environmental stimuli, the skin will be damaged to varying degrees. If the damage is severe, the function of internal organs will change, and may even result in death $(33,34)$. Therefore, it is crucial to identify methods with which to promote the efficiency of skin wound repair. As is known, the process of wound repair is very complex. The key factor in this process is the process of forming and reconstructing new tissue cells $(1,35)$. According to previous findings, SPCP enhances the proliferation and migration of human fibroblasts (28), which play a crucial role in the formation and remodeling of
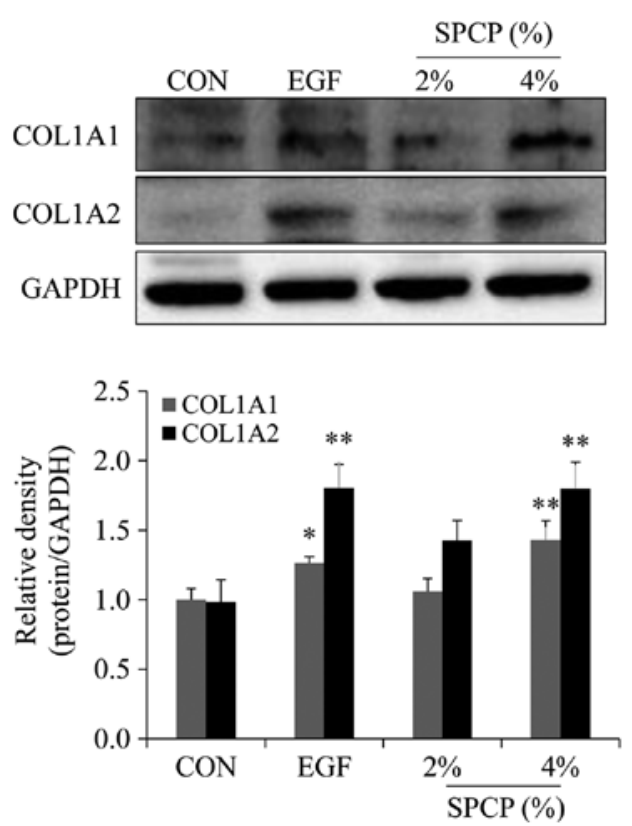

Figure 6. Treatment with SPCP enhances the protein expression of type I collagen in C57BL/6 mice. The protein expression levels of COL1A1 and COL1A2 in C57BL/6 mice were measured by western blot analysis following treatment with various concentrations of SPCP for 9 days. Each value represents the mean \pm standard deviation of three independent experiments. ${ }^{*} \mathrm{P}<0.05,{ }^{* *} \mathrm{P}<0.01$ compared to the control group. SPCP, spirulina protein; EGF, epidermal growth factor; COL1A1, collagen, type I, alpha 1.

new tissues. In the present study, SPCP was found to promote skin wound repair in $\mathrm{C} 57 \mathrm{BL} / 6$ mice. It has been reported that a low level of ROS is essential for wound repair. However, excessive ROS production can inhibit wound repair $(36,37)$. Superoxide anion free radicals $\left(\mathrm{O}_{2}^{-}\right)$are natural intermediates 
in various physiological reactions of organisms. These are a type of ROS with poten oxidation ability and are one of the important factors of biological oxygen toxicity. SOD is a free radical scavenger, which exists widely in various tissues of organisms and can scavenge free radical $\mathrm{O}_{2}^{-}$(38). CAT is an enzyme scavenger that can decompose hydrogen peroxide into water and oxygen. Hydrogen peroxide is scavenged by CAT to protect the body from oxidative damage (39). Antioxidants play an important role in wound repair due to its protection on the wound from oxidative damage (32). Thus, the present study evaluated the antioxidant effects of SPCP in wound repair by measuring the SOD, CAT activity and MDA content. The results revealed that SPCP reduced the MDA content. At the same time, the activities of SOD and CAT in the granulation tissue of mice in the SPCP treatment group were higher than those of the mice in the control group. These results suggest that SPCP promotes the repair of skin wounds in mice through antioxidation.

ERK1/2 can be phosphorylated by certain growth factors and hydrogen peroxide, and then enters the nucleus to act on transcription factors in the nucleus, such as c-Myc, c-Jun and nuclear factor $\kappa$-light-chain-enhancer of activated B cells $(\mathrm{NF}-\kappa \mathrm{B})(40)$. Therefore, ERK1/2 can promote the activity of downstream genes, affect the transcription and expression of downstream genes, regulate various functions of cells, such as metabolism and survival, and ultimately affect the corresponding biology of cells (41). It has been reported that only phosphorylated ERK1/2 is active (42). In a previous study, it was demonstrated that SPCP increased the phosphorylation level of ERK1/2 (27). Thus, the phosphorylation level of ERK1/2 in the granulation tissue of C57BL/6 mice was determined in the present study. The results revealed that SPCP activated ERK1/2 signaling in the skin granulation tissue of C57BL/6 mice. Moreover, the PI3K/Akt signaling pathway, as one of the more common signaling pathways in vivo, is involved in regulating various cell activities, such as cell inflammation, proliferation and differentiation (43). PI3K/Akt pathway integrates signals from growth factors and cytokines, and transmits these signals through multiple downstream effectors (44). In turn, these effectors regulate basic cellular functions, including growth, metabolism, survival and proliferation (45). Previous studies have found that SPCP activates the PI3K/Akt signaling pathway in CCD-986sk cells. Therefore, the activation of Akt signaling was examined in the present study. The results demonstrated that SPCP activated Akt signaling in the skin granulation tissue of C57BL/6 mice.

In the process of wound repair, wound contraction and ECM recombination are crucial (46). In the process of wound contraction, one of the most important factors is the expression and differentiation of myofibroblasts. The expression of $\alpha$-SMA is an important marker of myofibroblasts (47). In the present study, on the 9th day of wound repair, the expression level of $\alpha$-SMA in granulation tissue of SPCP treated mice was significantly higher than that of the control group. Previous studies have indicated that in the process of fibroblast differentiation into myofibroblasts, the stimulation of TGF- $\beta$ on wounds is crucial (7-9). In the present study, on the 9th day following injury, SPCP treatment significantly increased the expression of TGF- $\beta 1$ in the granulation tissue.
Moreover, the phosphorylation level of Smad2, which was the downstream signal of TGF- $\beta 1$, was enhanced by treatment with SPCP in the granulation tissue of C57BL/6 mice. These results suggested that SPCP promoted skin wound repair in mice by increasing the expression of $\alpha$-SMA and activating the TGF- $\beta 1 /$ Smad signaling pathway. For further research, the authors aim to determine the later events in wound healing, such as tissue normalization, reduction of $\alpha$-SMA (positive cells), TGF- $\beta 1$, and associated components or reconstitution of ROS levels, to assess whether SPCP may be used as an appropriate therapeutic. In addition, the cutaneous ECM comprises a complex assortment of proteins. The most abundant proteins in the ECM are collagens. In particular, type I collagen is the most prevalent of the fibril-forming collagens (48). According to previous studies, it has been found that SPCP promotes the secretion of collagen in CCD-986sk cells (27). In the present study, the expression level of type I collagen was determined in granulation tissue of $\mathrm{C} 57 \mathrm{BL} / 6$ mice. The results revealed that the expression level of type I collagen was induced by SPCP. In addition, other components of the ECM also play an essential role in wound repair, such as fibronectin which is an adhesive molecule that plays a crucial role in ECM formation and skin wound repair (49). Thus, further studies are required to determine the expression level of other components of the ECM in granulation tissue following treatment with SPCP. Even though the ECM plays an important role in skin wound repair, excessive ECM deposition may result in fibrosis, scarring and the loss of tissue function. Accordingly, it is important to maintain ECM production in balance for a complete closure of a wound.

In conclusion, in the present tudy, following SPCP treatment, the wound repair was enhanced in C57BL/6 mice. This indicated that SPCP can effectively promote wound repair. In this process, the ERK, Akt and TGF- $\beta 1$ signaling pathways played an important role. The results obtained herein provide evidence of the promoting effects of SPCP on wound repair in C57BL/6 mice and the underlying mechanisms were revealed. Furthermore, the results obtained in the present study support the positive role of SPCP in wound repair.

For further study, the authors aim to perform the specific staining of tissue sections to address appearance and location of critical components, cell and tissue fate of both skin compartments. In addition, despite the fact that C57/BL6 mice are a widely accepted wound repair model for experiments, the skin structure and wound repair mechanisms of the mice differ from those of humans. Further studies are thus required to evaluate the therapeutic effets of SPCP on other wound repair models that are more akin to the human skin.

\section{Acknowledgements}

Not applicable.

\section{Funding}

The present study was supported by the Basic Science Research Program through the National Research Foundation of Korea (NRF), funded by the Ministry of Education (grant no. 2012R1A6A1028677). 


\section{Availability of data and materials}

The analyzed datasets of this study are available from the corresponding author on reasonable request.

\section{Authors' contributions}

TJN was involved in the conceptualization of the study. PL and YHC were involved in data analysis. PL, MKL and JWC were involved in data analysis and investigation. PL was involved in the writing of the original draft. YHC was involved in the writing, reviewing and editing of the manuscript. TJN supervised the study and was responsible for funding acquisition. All authors read and approved the final manuscript.

\section{Ethics approval and consent to participate}

All experiments procedures were approved by the University Animal Care and Use Committee guidelines at Pukyong National University (Busan, Korea; approval no. 2018-15) and conducted according to the international regulations of the usage and welfare of laboratory animals.

\section{Patient consent for publication}

Not applicable.

\section{Competing interests}

The authors declare that they have no competing interests.

\section{References}

1. Kageyama $\mathrm{H}$ and Waditee-Sirisattha R: Antioxidative, antiinflammatory, and anti-aging properties of mycosporine-like amino acids: Molecular and cellular mechanisms in the protection of skin-aging. Mar Drugs 17: pii: E222, 2019.

2. Hyun YJ,Piao MJ, Kang KA,Zhen AX, Madushan Fernando PDS, Kang HK, Ahn YS and Hyun JW: Effect of fermented fish oil on fine particulate matter-induced skin aging. Mar Drugs 17: pii: E61, 2019.

3. Takeo M, Lee W and Ito M: Wound healing and skin regeneration. Cold Spring Harb Perspect Med 5: a023267, 2015.

4. Martin P: Wound healing-aiming for perfect skin regeneration. Science 276: 75-81, 1997.

5. Hu L, Wang J, Zhou X, Xiong Z, Zhao J, Yu R, Huang F, Zhang H and Chen L: Exosomes derived from human adipose mensenchymal stem cells accelerates cutaneous wound healing via optimizing the characteristics of fibroblasts. Sci Rep 6: 32993, 2016.

6. Chiquet M, Katsaros C and Kletsas D: Multiple functions of gingival and mucoperiosteal fibroblasts in oral wound healing and repair. Periodontol 2000 68: 21-40, 2015.

7. Barrientos S, Stojadinovic O, Golinko MS, Brem H and Tomic-Canic M: Growth factors and cytokines in wound healing. Wound Repair Regen 16: 585-601, 2008.

8. Crowe MJ, Doetschman T and Greenhalgh DG: Delayed wound healing in immunodeficient TGF-beta 1 knockout mice. J Invest Dermatol 115: 3-11, 2000.

9. Philipp K, Riedel F, Sauerbier M, Hörmann K and Germann G: Targeting TGF-beta in human keratinocytes and its potential role in wound healing. Int J Mol Med 14: 589-593, 2004.

10. Tracy LE, Minasian RA and Caterson EJ: Extracellular matrix and dermal fibroblast function in the healing wound. Adv Wound Care (New Rochelle) 5: 119-136, 2014.

11. Zhou ZQ, Chen Y, Chai M, Tao R, Lei YH, Jia YQ, Shu J, Ren J, Li G, Wei WX, et al: Adipose extracellular matrix promotes skin wound healing by inducing the differentiation of adipose-derived stem cells into fibroblasts. Int J Mol Med 43: 890-900, 2019.
12. Xue $M$ and Jackson CJ: Extracellular matrix reorganization during wound healing and its impact on abnormal scarring. Adv Wound Care (New Rochelle) 4: 119-136, 2015.

13. Guo S and Dipietro LA: Factors affecting wound healing. J Dent Res 89: 219-229, 2010.

14. Yang Y, Xia T, Zhi W, Wei L, Weng J, Zhang C and Li X: Promotion of skin regeneration in diabetic rats by electrospun core-sheath fibers loaded with basic fibroblast growth factor. Biomaterials 32: 4243-4254, 2011.

15. Moulin V: Growth factors in skin wound healing. Eur J Cell Biol 68: 1-7, 1995.

16. Derynck R, Zhang Y and Feng XH: Smads: Transcriptional activators of TGF-beta responses. Cell 95: 737-740, 1998.

17. Rolfe KJ, Richardson J, Vigor C, Irvine LM, Grobbelaar AO and Linge C: A role for TGF-beta 1-induced cellular responses during wound healing of the non-scarring early human fetus? J Invest Dermatol 127: 2656-2667, 2007.

18. Wynn TA: Cellular and molecular mechanisms of fibrosis. J Pathol 214: 199-210, 2008.

19. Sauer H, Wartenberg $M$ and Hescheler J: Reactive oxygen species as intracellular messengers during cell growth and differentiation. Cell Physiol Biochem 11: 173-186, 2001.

20. Dunnill C, Patton T, Brennan J, Barrett J, Dryden M, Cooke J, Leaper D and Georgopoulos NT: Reactive oxygen species (ROS) and wound healing: The functional role of ROS and emerging ROS-modulating technologies for augmentation of the healing process. Int Wound J 14: 89-96, 2017.

21. Sen CK, Khanna S, Babior BM, Hunt TK, Ellison EC and Roy S: Oxidant-induced vascular endothelial growth factor expression in human keratinocytes and cutaneous wound healing. J Biol Chem 277: 33284-33290, 2002.

22. Park HH, Park NY, Kim SG, Jeong KT, Lee EJ and Lee E: Potential wound healing activities of galla rhois in human fibroblasts and keratinocytes. Am J Chin Med 43: 1625-1636, 2015.

23. Pozzolini M, Millo E, Oliveri C, Mirata S, Salis A, Damonte G, Arkel $\mathrm{M}$ and Scarfì S: Elicited ROS scavenging activity, photoprotective, and wound-healing properties of collagen-derived peptides from the marine sponge chondrosia reniformis. Mar Drugs 16: pii: E465, 2018.

24. Son DH, Yang DJ, Sun JS, Kim SK, Kang N, Kang JY, Choi YH, Lee JH, Moh SH, Shin DM and Kim KW: A novel peptide, nicotinyl-isoleucine-valine-histidine (NA-IVH), promotes antioxidant gene expression and wound healing in $\mathrm{HaCaT}$ cells. Mar Drugs 16: pii: E262, 2018.

25. Kubatka P, Kapinová A, Kružliak P, Kello M, Výbohová D, Kajo K, Novák M, Chripková M, Adamkov M, Péč M, et al: Antineoplastic effects of Chlorella pyrenoidosa in the breast cancer model. Nutrition 31: 560-569, 2015.

26. Sheih IC, Fang TJ, Wu TK and Lin PH: Anticancer and antioxidant activities of the peptide fraction from algae protein waste. J Agric Food Chem 58: 1202-1207, 2010.

27. Liu P, Lee MK, Choi JW, Choi Y and Nam TJ: Crude protein from spirulina increases the viability of CCD-986sk cells via the EGFR/MAPK signaling pathway. Int J Mol Med 43: 771-778, 2019.

28. Liu P, Choi JW, Lee MK, Choi YH and Nam TJ: Wound healing potential of spirulina protein on CCD-986sk cells. Mar Drugs 17: pii: E130, 2019.

29. Plikus MV, Guerrero-Juarez CF, Ito M, Li YR, Dedhia PH, Zheng Y, Shao M, Gay DL, Ramos R, Hsi TC, et al: Regeneration of fat cells from myofibroblasts during wound healing. Science 355: 748-752, 2017.

30. Verrecchia F and Mauviel A: Transforming growth factor-beta signaling through the Smad pathway: Role in extracellular matrix gene expression and regulation. J Invest Dermatol 118: 211-215, 2002.

31. Wu HY, Wu JL and Ni ZL: Overexpression of microRNA-202-3p protects against myocardial ischemia-reperfusion injury through activation of TGF- $\beta 1 /$ Smads signaling pathway by targeting TRPM6. Cell Cycle 18: 621-637, 2019.

32. Joshi A, Joshi VK, Pandey D and Hemalatha S: Systematic investigation of ethanolic extract from Leea macrophylla: Implications in wound healing. J Ethnopharmacol 191: 95-106, 2016.

33. Zhao X, Wu H, Guo B, Dong R, Qiu Y and Ma PX: Antibacterial anti-oxidant electroactive injectable hydrogel as self-healing wound dressing with hemostasis and adhesiveness for cutaneous wound healing. Biomaterials 122: 34-47, 2017.

34. Kim HS, Park SY, Moon SH, Lee JD and Kim S: Autophagy in human skin fibroblasts: Impact of age. Int J Mol Sci 19: pii: E2254, 2018 . 
35. Pereira RF and Bártolo PJ: Traditional therapies for skin wound healing. Adv Wound Care (New Rochelle) 5: 208-229, 2016.

36. Schäfer M and Werner S: Oxidative stress in normal and impaired wound repair. Pharmacol Res 58: 165-171, 2008.

37. Landén NX, Li D and Ståhle M: Transition from inflammation to proliferation: A critical step during wound healing. Cell Mol Life Sci 73: 3861-3885, 2016.

38. Nimse SB and Pal D: Free radicals, natural antioxidants, and their reaction mechanisms. RSC Adv 5: 27986-8006, 2015.

39. Sies H: Hydrogen peroxide as a central redox signaling molecule in physiological oxidative stress: Oxidative eustress. Redox Biol 11: 613-619, 2017.

40. Meloche S and Pouysségur J: The ERK1/2 mitogen-activated protein kinase pathway as a master regulator of the G1-to S-phase transition. Oncogene 26: 3227-3239, 2007.

41. He Z, Jiang J, Kokkinaki M, Golestaneh N, Hofmann MC and Dym M: Gdnf upregulates c-Fos transcription via the Ras/Erk1/2 pathway to promote mouse spermatogonial stem cell proliferation. Stem Cells 26: 266-278, 2008.

42. Mebratu Y and Tesfaigzi Y: How ERK1/2 activation controls cell proliferation and cell death: Is subcellular localization the answer? Cell Cycle 8: 1168-1175, 2009.

43. Coutant A, Rescan C, Gilot D, Loyer P, Guguen-Guillouzo C and Baffet G: PI3K-FRAP/mTOR pathway is critical for hepatocyte proliferation whereas MEK/ERK supports both proliferation and survival. Hepatology 36: 1079-1088, 2002.
44. Engelman JA, Luo J and Cantley LC: The evolution of phosphatidylinositol 3-kinases as regulators of growth and metabolism. Nat Rev Genet 7: 606-619, 2006.

45. Kornasio R, Riederer I, Butler-Browne G, Mouly V, Uni Z and Halevy O: Beta-hydroxy-beta-methylbutyrate (HMB) stimulates myogenic cell proliferation, differentiation and survival via the MAPK/ERK and PI3K/Akt pathways. Biochim. Biophys Acta 1793: 755-763, 2009.

46. Schultz GS and Wysocki A: Interactions between extracellular matrix and growth factors in wound healing. Wound Repair Regen 17: 153-162, 2009.

47. Hinz B: Formation and function of the myofibroblast during tissue repair. J Invest Dermatol 127: 526-537, 2007.

48. Kadler KE, Baldock C, Bella J and Boot-Handford RP: Collagens at a glance. J Cell Sci 120: 1955-1958, 2007.

49. Lenselink EA: Role of fibronectin in normal wound healing. Int Wound J 12: 313-316, 2015.

(i) This work is licensed under a Creative Commons Attribution-NonCommercial-NoDerivatives 4.0 International (CC BY-NC-ND 4.0) License. 